\title{
Small Scale Refrigerators and Freezers: Thermal Improvements in the Envelope
}

\author{
Clito Afonso ${ }^{1,2}$ and Joaquim Gabriel ${ }^{3}$ \\ 1. Department Mechanical Eng ${ }^{a}$, Faculty of Engineering of Porto University, Porto, R. Dr. Roberto Frias, 4200-465 Porto, Portugal \\ 2. Centre for Renewable Energy Research-CIENER University of Porto, R. Dr. Roberto Frias, 4200-465 Porto, Portugal \\ 3. INEGI, R. Dr. Roberto Frias, 4200-465 Porto, Portugal
}

\begin{abstract}
Like in other sectors of activity, the sustainability in refrigeration systems is a mandatory goal to achieve, namely at house holdings, bars and restaurants, where small-scale refrigerators and freezers are widely used. The aim of this work is to demonstrate experimentally, trough measurements carried out in these equipments, the improvement that can be achieved if several modifications are implemented in traditional household refrigeration systems. In addition, it was also simulated and analysed experimentally a slightly different equipment, a refrigeration system used for draught beverages. Both systems work on a single vapour compression refrigeration with R-134a as working fluid. In the end, by implemented the modifications tested in the virtual model, it was possible to improve their thermal behaviour, a decrease in electrical energy consumption, as well as, the associated $\mathrm{CO}_{2}$ emissions reduction can be attained. In this project, the CFD (Computational Fluid Dynamics) software-ANSYS Fluent was used to simulate the ambient temperature and velocity fields inside the refrigerator and in that way to validate the measured results.
\end{abstract}

Key words: Small scalerefrigerators/freezer, thermal efficiency, air infiltration, sustainability, $\mathrm{CO}_{2}$ emissions reduction.

\section{Introduction}

The IIR (International Institute of Refrigeration) estimates that there are in operation throughout the world about 3,000 million refrigeration systems, which represent about $17 \%$ of the electricity used [1]. In order to achieve a better efficiency, several research works have been carried out in all individual components of these systems namely compressors, evaporators, condensers, expansion systems, different arrangements and working fluids [2-12].

However, care must be taken regarding the envelope where the systems are located, due to the heat and water vapour transfer from outside to inside of the refrigerated space.

In cold storage chambers, where there is the possibility of water vapour condensations inside the walls, the placement of vapour barriers in the warmer

Corresponding author: Clito Afonso, Ph.D., main research fields: applied thermodynamics. side of the insulation will solve the problem [13]. However, in the small scale refrigerators/freezers, they already have total limiting barriers, aluminium foils or plastic type, which prevents the vapour migration through the system. So this investigation concerns other possible ways to minimize the heat transfer through the envelope, mainly in the rear wall, nearby the condenser and in the compressor recess. Due to the heat released in these equipments, the surface temperature is higher when compared with the other external surfaces. As a consequence, heat will flow through those nearby walls to the internal air of the refrigerator, with negative consequences for the refrigeration process itself and for the energy consumption.

In this paper, two kind of systems are analysed: one is a commercial household refrigerate and the second is a refrigeration system for draught beverages. Both of them operate in a single vapour compression cycle, and use R-134a as a working fluid. The systems were 
also modelled using ANSYS Fluent software [14] to visualize the air temperatures and velocity fields inside the refrigerator and to validate the model with the experimental results.

This article is organized as follows: chapter 2 describes the changes implemented in the systems; chapter 3 shows the experimental results and the chapter 4 presents the final conclusions of this work.

\section{Experimental Setup}

This work concerns with energy improvements that were performed in two different types of small-scale refrigerators, for household use and for draughter beer machines.

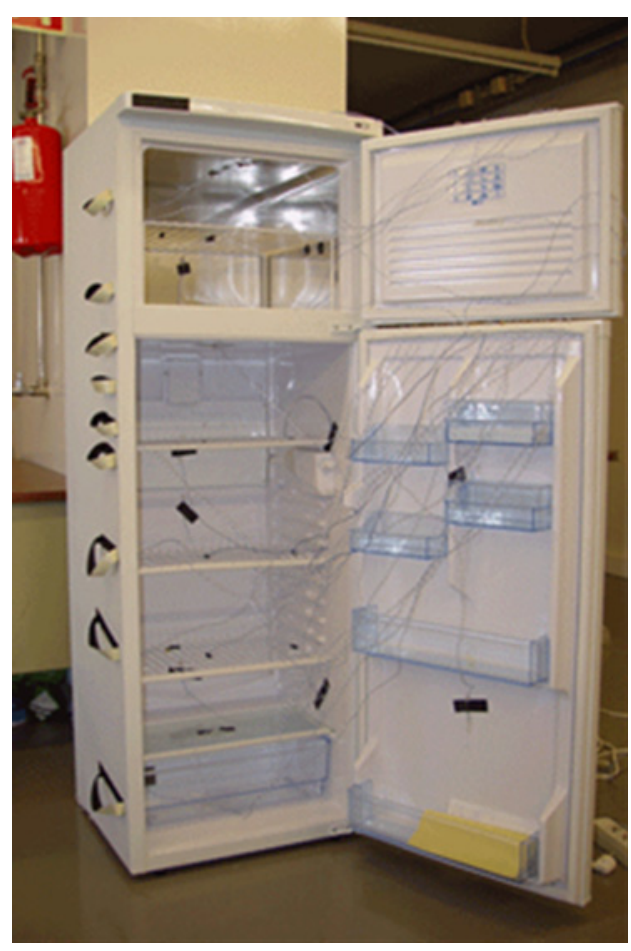

(a) The refrigerator

\subsection{Refrigerator/Freezer}

The refrigerator is composed of a freezer cabinet in the upper part (inside air negative temperatures) and a refrigerator cabinet in the lower part (inside air positive temperatures) as can be seen in Fig. 1a. By analysing the actual measured temperatures and pressures, one noticed that there is a larger heat transfer through the rear wall and in the compressor recess to the inside air of the refrigeration cabin. This is due to the fact that these surfaces have higher temperatures than the other surfaces of the envelope. To minimize this loss, a radiation shield $(r s)$ made of aluminium foil was placed in the rear wall, in the

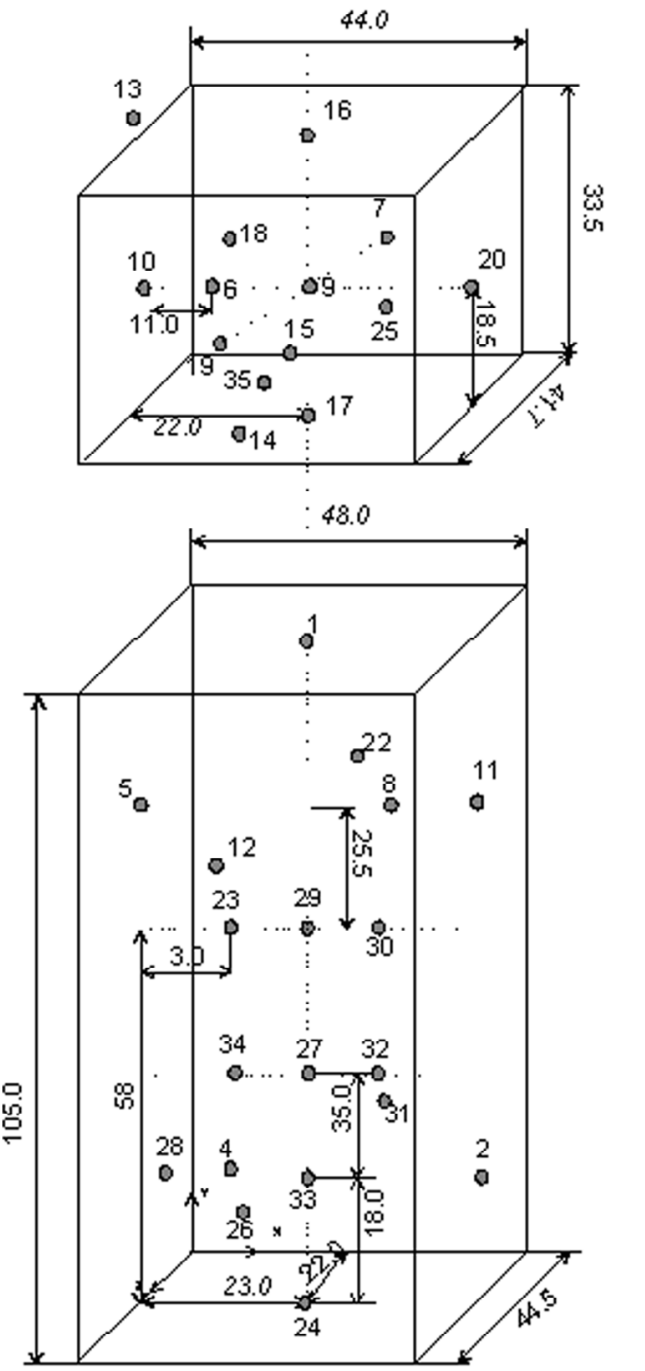

(b) Location of the thermocouples inside the refrigerator

Fig. 1 The refrigeration with the locations of the thermocouples. 
compressor recess and in both of them. At the beginning of the tests, the refrigeration/freezer was in thermal equilibrium with the ambient air (the doors were open). The tests were carried out with the refrigerator empty and ended when steady state was reached, i.e., when the refrigeration cycles were similar. The temperature was monitored with thermocouples (K type) in several locations on the inside surfaces, outside surfaces, inside air temperatures in both compartments and outside ambient air temperature (Fig. 1b). The measured values were recorded in a data logger that reads all temperatures in 20 seconds intervals. At the same time, the compressor power and energy consumption were measured and the results were saved for posterior analysis.

A second type of tests were done with the same refrigerator, where a plenum with forced air

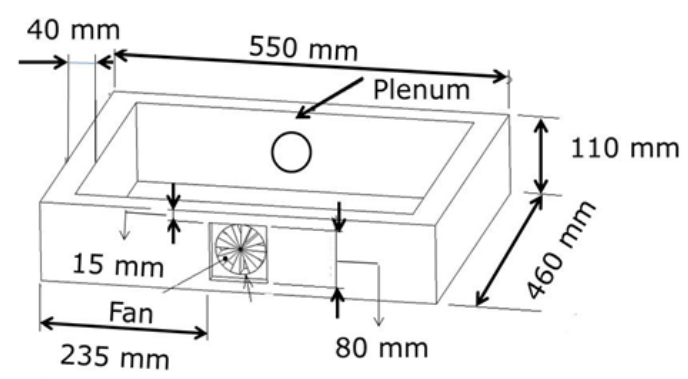

Depth of the fan: $25 \mathrm{~mm}$

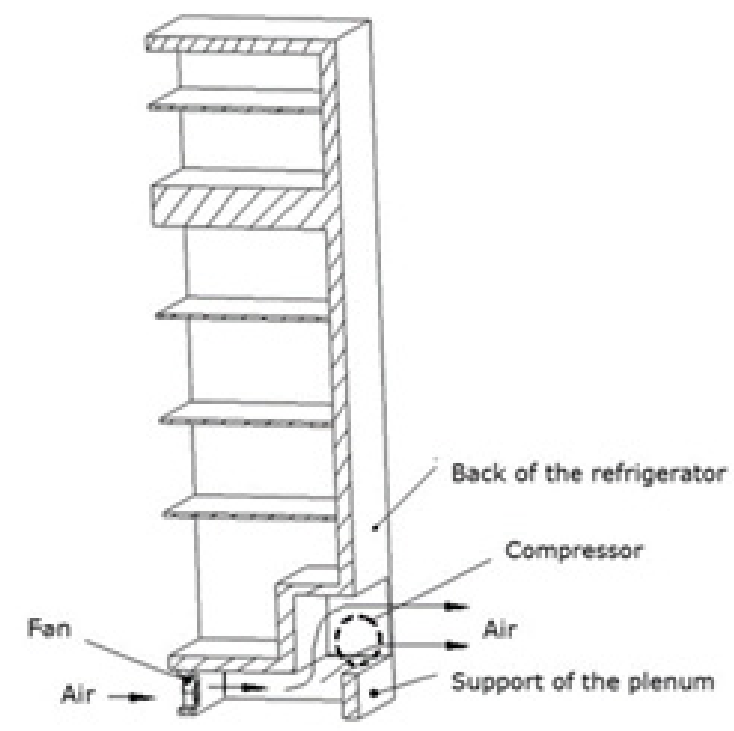

Fig. 2 Dimensions and location of the plenum. convection was located in the compressor recess, in order to decrease the high temperatures measured at this site (Fig. 2). In this way, it was created a smaller heat transfer through the bottom surface of the refrigerator and, as a consequence, it results in a lower energy consumption of the compressor, while the power of the fan was only $1.43 \mathrm{~W}$.

A third set of tests were carried out to evaluate the air infiltration through the magnetic seals of the refrigerator/freezer in order to estimate the heat transfer through them. This test was done using a tracer gas, as described in [15].

The old seal was replaced by a new one (Fig. 3), and the influence on the thermal load was evaluated, as well as, the power consumption of the compressor and the corresponding avoided emission of $\mathrm{CO}_{2}$ to the environment.
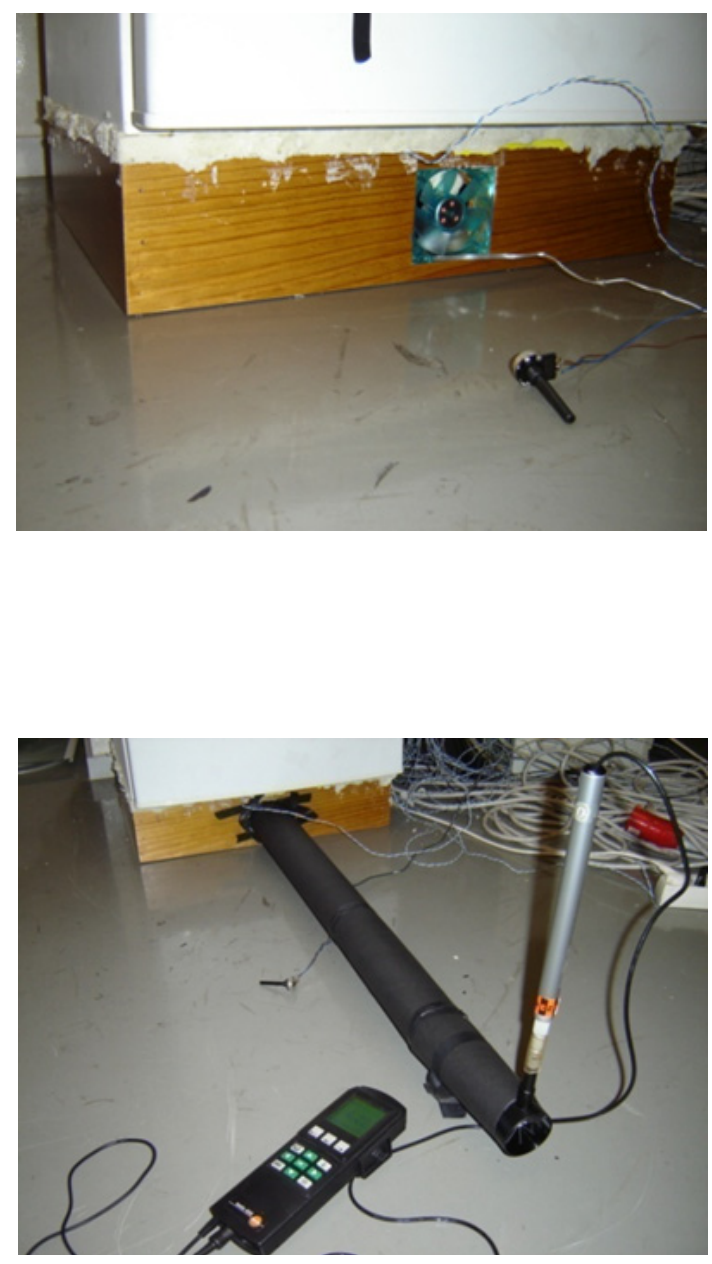


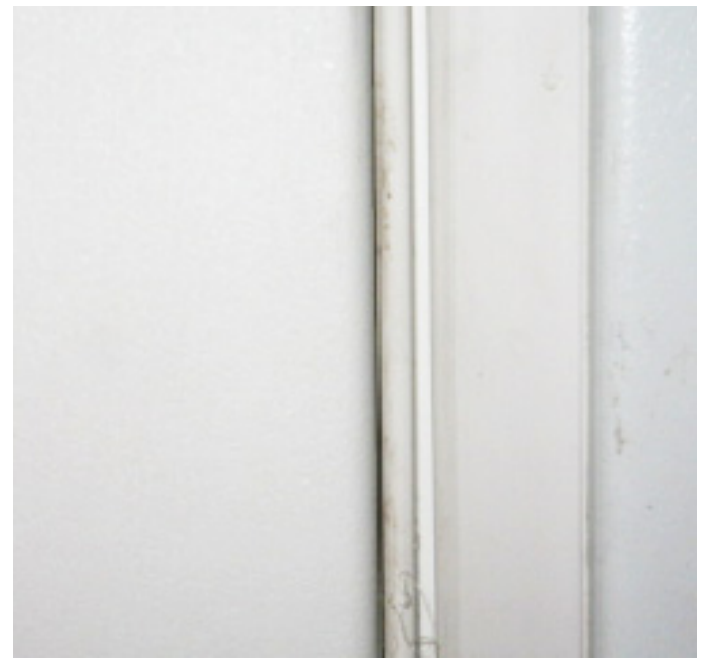

New seal

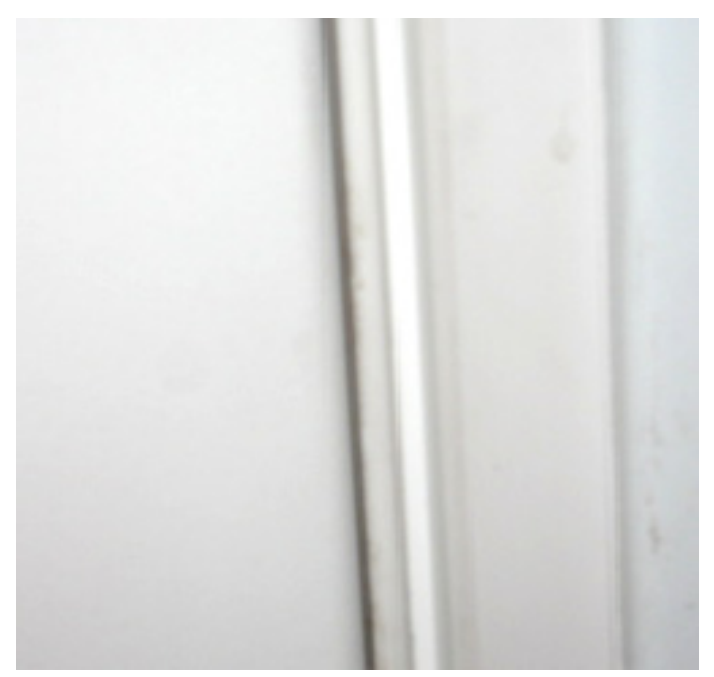

Old seal

Fig. 3 Magnetic seals.

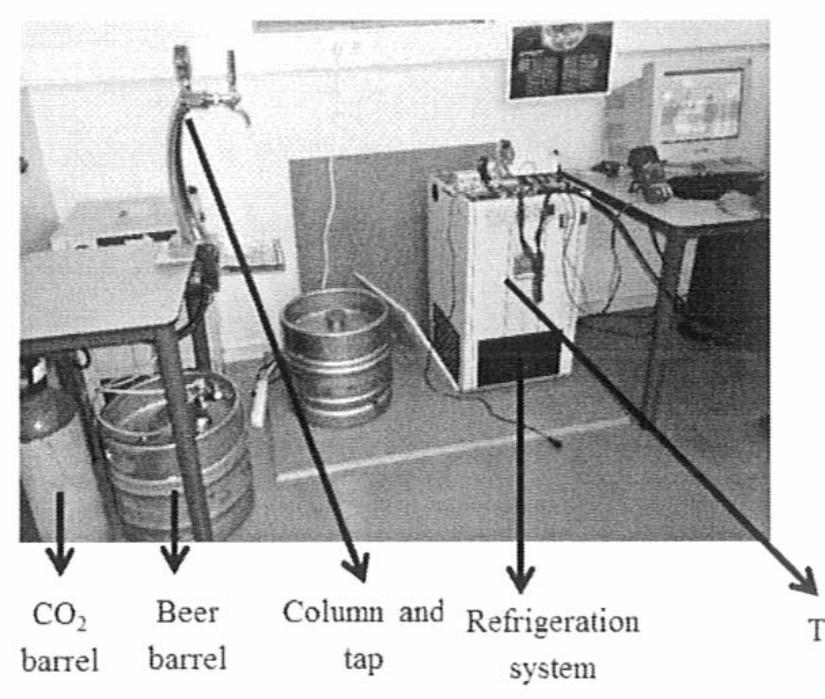

(a) Overall view

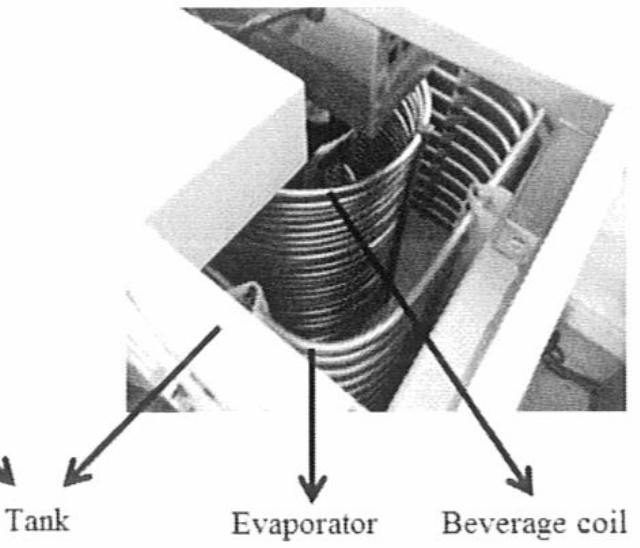

(b) Tank (ice deposit)

Fig. 4 Global system of the draught drinks.

\subsection{Refrigeration System for Draught Beverages}

Fig. 4 shows the second refrigeration system, used for draught beverages. After a detailed analysis, it was concluded that several improvements could be carried out, namely switching off the system (when the establishment is closed, there is no beverage consumption) and modifying the layout of the system.

The iced water deposit has a capacity of $50 \mathrm{~L}$, being designed to operate normally with about $25 \mathrm{~kg}$ of ice mass. Thus, it was analysed the energy consumption of the system if lower ice mass is produced. In order to better visualise the inefficiencies of the system, thermal images of the machine during normal operation were taken, using the thermal camera (Flir A325).

\section{Results}

\subsection{Refrigerator}

\subsubsection{Refrigerator with Radiation Shields}

As mentioned before, the first type of tests was composed by three different analyses: placement of radiation shields in the rear wall, in the compressor 
recess and in both sites.

Table 1 summarizes the results obtained in the three situations regarding the refrigerating cycle operation [16].

From the data of Table 1, it can be concluded that the cycle period is longer when compared with the refrigerator-freezer in its original situation, due to the increased time the compressor remains off, which decreases the electrical energy use.

Regarding the time to reach the steady state: no conclusion can be withdrawn, as there is a significant reduction in time when the $r s$ is located only in the rear wall and only in the compressor recess; while there is an increase of the time when $r s$ is located over both surfaces ( 1 minute more than the original situation).

The air temperatures inside the refrigerator along its height were also measured and the results are displayed in Table 2.

By analysing the data in Table 2, it can be seen that the minimum air temperature decreases from top to the bottom of the refrigerator, except for the lower level (located at a height of $35 \mathrm{~cm}$ ) that is in average slightly higher than the immediate upper level (height of $53 \mathrm{~cm}$ ). As these air temperatures are reached when the compressor is not working, this can be explained by the cooling effect of the evaporator. The minimum inside air temperatures are attained when the radiation shield is mounted on the rear wall and compressor recess. Additionally, $r s$ has a positive effect on the air temperatures inside the freezer system.

On average, the maximum air temperatures inside the refrigerator (when the compressor is about to start running) increases from bottom to the top due to the heat gained through the walls. Again, if $r s$ is located in the rear wall of the refrigerator and in the compressor recess, then it has the effect of lowering the inside air temperatures.

\subsubsection{Refrigerator with a Plenum}

The second type of test was done with the same refrigerator, where a plenum with forced air convection was located in the compressor recess, as shown in Fig. 2. In this case, several tests were done, as shown in Fig. 5 (The refrigerator without plenum, and internal load test \#1 and test \#2 with internal load). The remaining tests were carried out with the base mechanical cooling, with and without thermal loads and with different fan velocities. The main results are shown in Table 3 [17], where the annual energy savings as well as the avoided $\mathrm{CO}_{2}$ emissions are shown for the refrigerator, in the last two columns.

As can be seen, there are savings in all tests, regarding the global electricity consumption and the correspondent decrease in $\mathrm{CO}_{2}$ emissions. So the proposed technology is therefore recommended.

Table 1 Compressor cycle operation for different locations of the radiation shield.

\begin{tabular}{lllll}
\hline Radiation shield $(r s)$. & Cycle time (min.) & Stopped (\%) & Running(\%) & Time to reach steady state (min.) \\
\hline Without & 33.3 & 61.0 & 39.0 & 51 \\
Rear wall & 35.3 & 61.3 & 38.6 & 42 \\
Comp. recess & 34.3 & 62.1 & 37.8 & 42 \\
Rear wall + comp. recess & 36.3 & 62.4 & 37.6 & 52 \\
\hline
\end{tabular}

Table 2 Minimum and maximum inside air temperature at different heights in the refrigerator $\left({ }^{\circ} \mathrm{C}\right)$ for different locations of $r$. Note: $T_{\text {aver. }}$ - temperature average inside the refrigerator, standard deviation.

\begin{tabular}{lllll}
\hline Height $(\mathrm{cm})$ & Without $r s$ & Rear wall with $r s$ & Recess with $r s$ & Rearwall + recess with $r s$ \\
\hline 83.5 & $4.5 / 6.6$ & $4.3 / 6.9$ & $4.1 / 5.9$ & $3.9 / 6.3$ \\
58 & $3.8 / 7.0$ & $2.6 / 6.9$ & $3.7 / 6.3$ & $2.5 / 5.2$ \\
53 & $2.9 / 7.4$ & $1.8 / 6.3$ & $2.5 / 6.1$ & $1.1 / 5.1$ \\
35 & $3.1 / 6.5$ & $2.3 / 5.7$ & $2.2 / 5.3$ & $1.8 / 5.6$ \\
$\mathrm{~T}_{\text {aver. }}$ & $3.6 / 6.9$ & $2.8 / 6.5$ & $3.1 / 5.9$ & $2.3 / 5.5$ \\
$\sigma$ & $0.6 / 0.35$ & $0.93 / 0.49$ & $0.79 / 0.37$ & $1.0 / 0.47$ \\
\hline
\end{tabular}




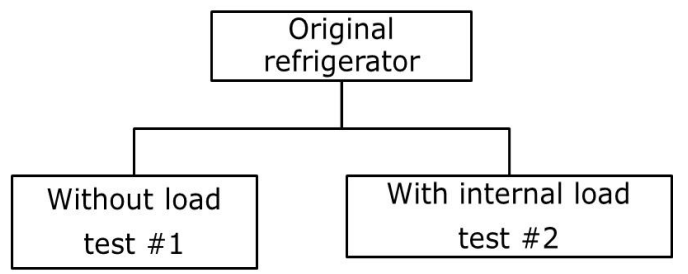

\begin{tabular}{c|c|c|}
$\begin{array}{c}\text { Refrigerator } \\
\text { with base } \\
\text { mechanical } \\
\text { cooling }\end{array}$ & $\begin{array}{c}\text { Ventilation velocity } \\
(100 \%)-\text { test } \# 3\end{array}$ \\
$\begin{array}{c}\text { Wentilation velocity } \\
(50 \%)-\text { test } \# 4\end{array}$ \\
$\begin{array}{c}\text { With } \\
\text { internal } \\
\text { load }\end{array}$ & $\begin{array}{c}\text { Ventilation velocity } \\
(100 \%)-\text { test } \# 5\end{array}$ \\
$\begin{array}{c}\text { Ventilation velocity } \\
(50 \%)-\text { test \#6 }\end{array}$ \\
\hline
\end{tabular}

Fig.5 Procedure of the experimental work.

Taking into account that the probable number of domestic refrigerators in the world is around 1,000 million [18], the global savings in energy consumption and avoided $\mathrm{CO}_{2}$ emissions if all the household refrigerators were similar to one tested in this work and were equipped with this proposed system, as shown in Table 4.

3.1.3 Leakage through the Magnetic Seals (Old/New Ones)

In order to evaluate the influence of the air leakage through the old versus new magnetic seals, upon the energy and power consumed in the refrigeration and freezer cabinet, it was first necessary to measure the air infiltration rate $I$ of the refrigerator through them. This goal was achieved using the tracer gas technique $[19,20]$. With the measurements carried out, it was possible to evaluate the energy consumed [21] as shown in Table 5.

In Table 6, it can be seen the electrical compressor energy and power regarding the replacement of the seals on $1 \mathrm{~h}$ basis.

Table 3 Energy saved per refrigerator and per year and the reduction of $\mathrm{CO}_{2}$ emissions to the environment.

\begin{tabular}{lllllll}
\hline TEST & Cycling time $[\mathrm{h}]$ & $\begin{array}{l}\text { Compressor } \\
\text { running time }[\mathrm{h}]\end{array}$ & Fan off time $[\mathrm{h}]$ & $\begin{array}{l}\text { Savings per cycle } \\
{[\mathrm{Wh}]}\end{array}$ & $\begin{array}{l}\text { Annual savings } \\
{[\mathrm{kWh}]}\end{array}$ & $\begin{array}{l}\mathrm{CO}_{2} \text { avoided } \\
\mathrm{emissions} \\
{\left[\mathrm{kgCO}_{2}\right]}\end{array}$ \\
\hline$\# 1$ & 0.483 & 0.161 & - & - & - & - \\
$\# 2$ & 0.467 & 0.161 & - & - & - & - \\
$\# 3$ & 0.483 & 0.156 & 0.328 & 0.492 & 9 & 4.2 \\
$\# 4$ & 0.456 & 0.139 & 0.317 & 0.452 & 8.6 & 4 \\
$\# 5$ & 0.461 & 0.161 & 0.300 & 0.429 & 8 & 3.8 \\
\hline 6 & 0.444 & 0.156 & 0.289 & 0.396 & 7.7 & 3.6 \\
\hline
\end{tabular}

Table 4 Annual energy savings and $\mathrm{CO}_{2}$ emissions reduction for all the estimated domestic household refrigerators in the world.

\begin{tabular}{lll}
\hline TEST & Annual savings $\left[\mathrm{MWh} \cdot 10^{3}\right]$ & Avoided $\mathrm{CO}_{2}$ emissions $\left[\right.$ tons $\left.\mathrm{CO}_{2} \cdot 10^{3}\right]$ \\
\hline$\# 1$ & - & - \\
$\# 3$ & 9,000 & 4,200 \\
$\# 4$ & 8,600 & 4,000 \\
$\# 2$ & - & - \\
$\# 5$ & 8,000 & 3,800 \\
$\# 6$ & 7,700 & 3,600 \\
\hline
\end{tabular}

Table 5 Power and energy associated to $I$ on $1 \mathrm{~h}$ basis.

\begin{tabular}{lllllll}
\hline Seal & Cabin & $\mathrm{I}[\mathrm{ACH}]$ & $\mathrm{R}^{2}[\mathrm{ACH}]$ & $\dot{Q}[W]$ & $\mathrm{Q}[\mathrm{Wh}]$ & Total Q [Wh] \\
\hline \multirow{2}{*}{ New } & Refrigerator & 2.1 & 0.95 & 2.35 & 2.35 & 3.28 \\
& Freezer & 1.1 & 0.97 & 0.93 & 0.93 & 14.2 \\
Old & Refrigerator & 12.7 & 0.97 & 14.2 & 5.8 & 19.9 \\
& Freezer & 6.7 & 0.98 & 5.8 & 504 & 506 \\
\multirow{2}{*}{ Decrease (\%) } & Refrigerator & 505 & & & 524 & 506 \\
& Freezer & 509 & & & & \\
\hline
\end{tabular}


Table 6 Electrical consumption associated to $\mathrm{I}$ on $1 \mathrm{~h}$ basis.

\begin{tabular}{llll}
\hline Seal & Compressor power [W] & Compressor energy [Wh] & \% of Energy to I \\
\hline Old & 63.7 & 63.7 & 31.3 \\
New & 45.5 & 45.5 & 7.1 \\
Decrease (\%) & 40 & 40 & 341 \\
\hline
\end{tabular}

The conclusions that can be withdrawn are: the air infiltration rate is always larger on the refrigerator cabin when compared with the freezer one, almost double, either with the new and old seals. This occurs because the air temperature differential between inside and outside air is larger on the freezer cabin and so the pressure differential. The consequence is that the freezer seal is much more compressed, minimizing on that way the air infiltration rate to the cabin.

The decrease of the air infiltration rate due to the change of the old seals by the new ones is respectively $505 \%$ for the refrigerator cabin and 509\% for the freezer compartment, which reflects on the energy consumed by the compressor that shows a total decrease of $341 \%$ on the electricity used.

The total energy related to the air infiltration is 3.28 Wh with the new seals and 19.9 Wh with old seals. This difference represents a reduction of $8.2 \mathrm{Wh}$ on the energy consumed by the compressor, which seems a very small quantity. The increase of the air infiltration rate due to the change of the new seals by the old ones is respectively $505 \%$ for the refrigerator cabin and 509\% for the freezer compartment, which reflects on the energy consumed by the compressor that shows a total increase of $341 \%$ on the electricity consumed.

Assuming the same number of refrigerators in the world (as before), the electrical energy that could be saved if the seals were replaced by new ones would be around $5.8 \mathrm{GWh} /$ year in all world. Taking into account that the world population in 2005 was about 6.5 billion, and on average, assuming that there are four members per family and only $50 \%$ of the families have refrigerators similar to the one tested, there will exist on earth 812.5 millions of refrigerators. Assuming now that in one fifth of them the seals were not in good conditions, the electrical energy that could be saved if the seals were replaced by new ones would be around $5.8 \mathrm{GWh} /$ year in all world. Now this is a huge number. Taking into account that, on average there is a production of $0.6 \mathrm{~kg}$ of $\mathrm{CO}_{2}$ per $\mathrm{kWh}$ as final energy, the total emissions of $\mathrm{CO}_{2}$ to the environment could be reduced by 3.5 billion of tons per year.

\subsection{Refrigeration System for Draught Drinks}

The refrigeration machine for draught drinks, already shown in Fig. 4, are used in almost every catering services. Their working principles are similar to the one displayed in Fig. 6 (showing the location of temperature and pressure sensors installed) and is composed of two subsystems, namely the refrigeration machine itself and the beverage subsystem. The tank is sited on the top of the first one, where all the coils for heat exchange are located and immersed in ice water (around $0{ }^{\circ} \mathrm{C}$ ).

This tank is responsible for the heat exchange between the evaporator coil (made of copper) and the iced water, and then from this last one to the beverage coil (made of stainless steel). To promote the heat exchange between both coils, and to maintain an almost constant temperature inside the tank, there is a stirring apparatus placed in its centre.

The production of iced water by the refrigeration system is an intermediate process to cool down the beverage from the ambient temperature to about $3{ }^{\circ} \mathrm{C}$. This temperature is not the desired goal itself. The formation of ice is the drawback in the whole system, as it is a major energy consumer. However, it represents a necessary buffer to help the maintenance of the temperature, even in the event of temporary failure, or lack of power of the refrigeration system. 


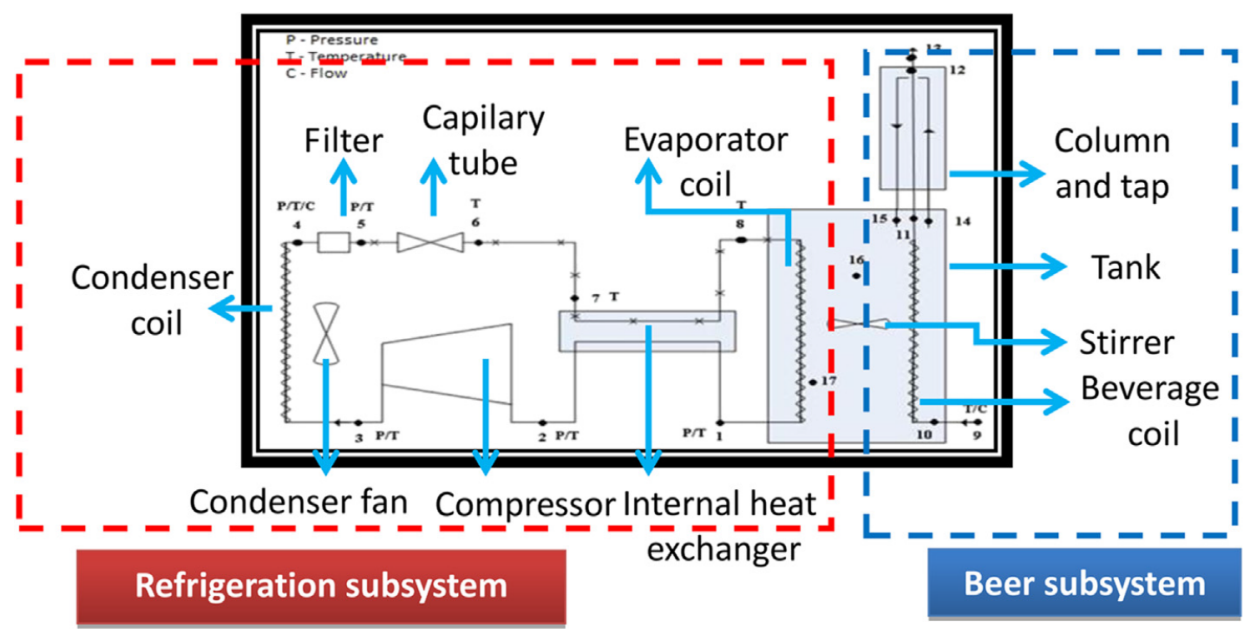

(a)

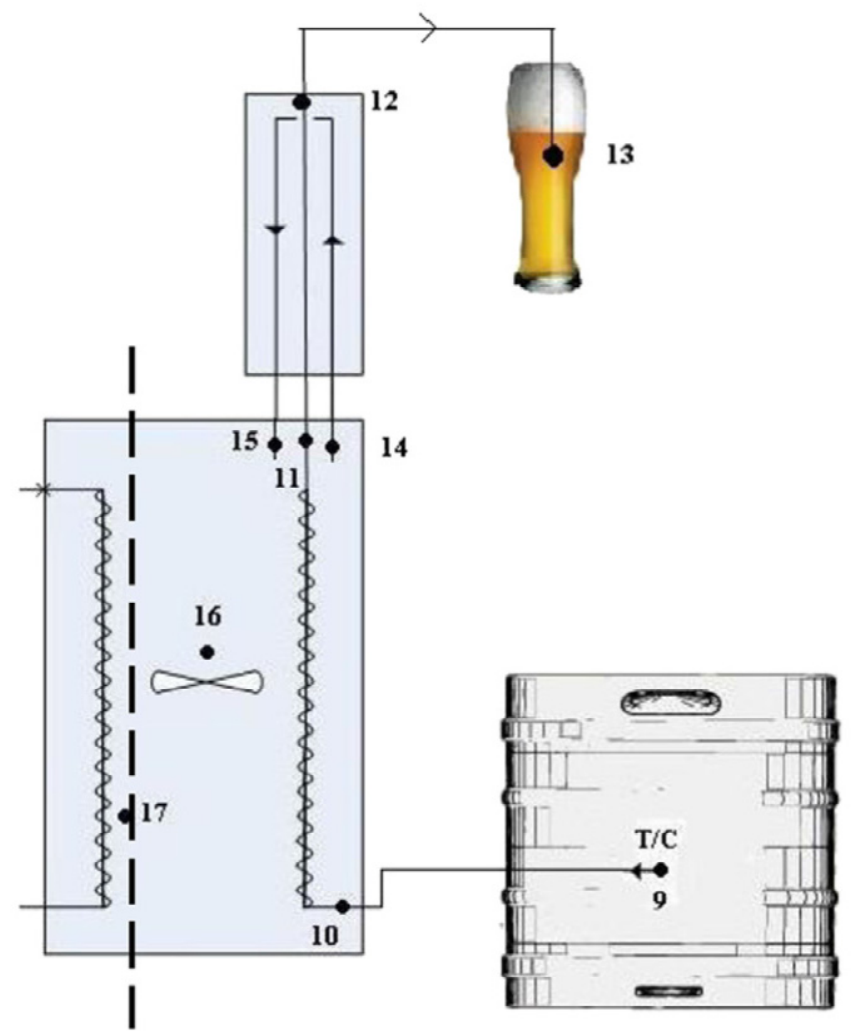

(b)

Fig. 6 (a) The two sub systems and location of all sensors, P-Pressure, T-Temperature. (b) Beverage subsystem (right of dashed line) and the location of the temperature sensors.

All the heat gains through the system were calculated in a previous published work [22]. In order to evaluate the efficiency of the whole system, several typical situations were simulated: small restaurants and bars during winter and summer time. To evaluate the beverage consumption scenarios in both kinds of establishments, a questionnaire was made in several similar establishments. The results presented, concerns only with the bar in summer time (Table 7) [23], as it is the worst situation due to the higher ambient temperatures and beverage consumption (the conclusions obtained in the remaining situations are 
similar). Fig. 7 displays the measured values of temperatures and pressure in the refrigeration system itself, while Table 8 shows the calculation done with the measured data. There are two COP (Coefficient of Performance) that can be evaluated: the COP of the refrigeration system itself to produce ice, $\mathrm{COP}_{\mathrm{R}}(\mathrm{Eq}$. (1)) and the COP of the global system, $\mathrm{COP}_{\mathrm{G}}$. Here the aim of the system is to cool down the beverage from the ambient air temperature to the one in the consumption tap (Eq. (2)):

$$
\begin{aligned}
& \operatorname{COP}_{R}=\frac{\dot{Q}_{\text {evap }}}{\dot{W}} \\
& \operatorname{COP}_{G}=\frac{\dot{Q}_{\text {bev }}}{\dot{W}}
\end{aligned}
$$

As a factory set, it was fixed an initial mass of ice of $25 \mathrm{~kg}$, which corresponds about $30 \mathrm{~mm}$ thickness around the beverage coil. The ice mass is monitored by a probe placed in the evaporator and connected to the control module. The thickness of ice can be adjusted by moving the ice detector away or in the direction of the wall, in order to obtain different ice masses. The ice detector prevents all water to freeze, turning off the system when it reached a predefined limit for the thickness of the ice on the coil. Several initial ice masses were simulated, respectively, 10, 21 and $25 \mathrm{~kg}$ in order to evaluate if with the beverage consumption there is not a lack of ice inside the tank during the running time of the system (Table 9).

It can be concluded that the initial mass of ice doesn't affect the $\mathrm{COP}_{\mathrm{R}}$ or the total energy consumption. So, it can be seen that lowering the amount of ice in no way compromises the functioning of the machine since all along the day there is ice being formed within the machine.

\section{Table 7 Beverage consumption (glasses of $200 \mathrm{~mL}$ ). Bar in summer time.}

\begin{tabular}{ll}
\hline Time $[\mathrm{hh}: \mathrm{mm}]$ & Consumption $\left[\mathrm{n}^{\mathrm{o}}\right.$ of glasses] \\
10:00 until 14:00 & No consumption \\
14:00 until 22:00 & 60 \\
22:00 until 02:00 & 800 \\
02:00 until 10:00 & 0 \\
\hline
\end{tabular}

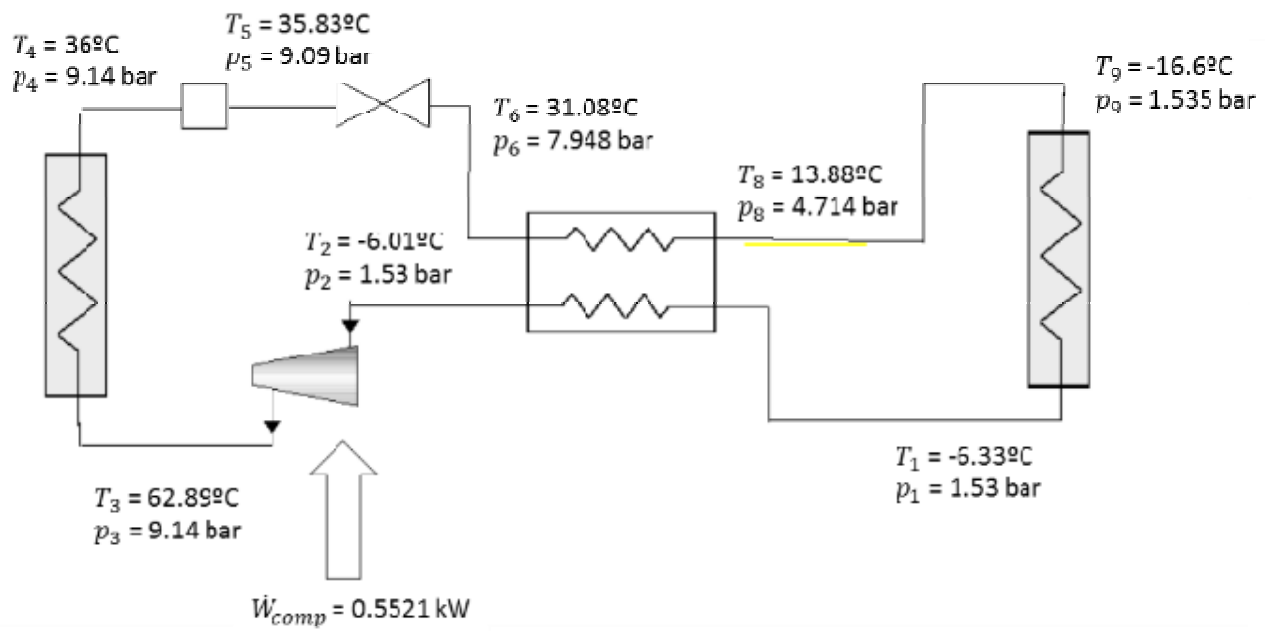

Fig. 7 Diagram of the refrigerating machine as well as the measured thermodynamic properties of the various states and the compressor power.

Table 8 Results of the thermodynamic analysis of the refrigeration cycle.

\begin{tabular}{llllllll}
\hline $\begin{array}{l}\dot{W}_{\text {comp }} \\
{[\mathrm{W}]}\end{array}$ & $\dot{m}$ & $\eta_{\text {is,comp }}$ & $\begin{array}{l}\dot{Q}_{\text {cond }} \\
{\left[\mathrm{kg} \cdot \mathrm{s}^{-1}\right]}\end{array}$ & $\begin{array}{l}\dot{Q}_{\text {evap }} \\
{[\%]}\end{array}$ & $\begin{array}{l}\eta_{\mathrm{HE}} \\
{[\mathrm{W}]}\end{array}$ & $\begin{array}{l}\dot{Q}_{\text {filter }} \\
{[\mathrm{W}]}\end{array}$ & $\begin{array}{c}\mathrm{COP}_{\mathrm{R}} \\
{[-]}\end{array}$ \\
\hline 552 & 0.01262 & 80.8 & 2469 & 1912 & 1.5 & 3.2 & 3.14 \\
\hline
\end{tabular}




\subsubsection{Improvements of the System}

Internal heat exchanger: as displayed in Table 8, the efficiency of the internal heat exchanger is extremely low: $1.5 \%$. The refrigeration system could benefit too much if a new design of that equipment was done.

Continuous operation: the draught machine presents a second inefficiency, it is working $24 \mathrm{~h}$ a day. So, when the establishment is closed, there is a large energy consumption without any profit (no beverage consumption). To diminish it, the system may be switched off during the closing time. As analysed, while the initial mass of ice in the tank doesn't affect the energy consumption of the system when it works permanently (there is always ice in the tank), in the case of switching it off during the closing period, it affects, because when the establishments opens, the deposit must already have the initial mass of ice inside (Table 10). It is also shown that with annual electrical energy savings, there are significant avoided $\mathrm{CO}_{2}$ emissions. The period during which the system can be turned off is assumed to be 12 hours, taking into account a margin of safety to any beverage that may be requested before noon.

Implementation: a real time clock should be connected to the system in a way that it switches off the whole system when the establishment is closed and switch it on some time before opening. With this strategy, the tank would have the necessary initial mass of ice needed when the establishment opens.

Bottom surface: the bottom surface of the tank is submitted to a larger temperature difference when compared to the top and vertical surfaces causing a larger heat gains to the iced water. Fig. 8 shows a thermal image of the machine during normal operation (left one), using the thermal camera (Flir A325) and in right one, the outside view. As mentioned and as can be seen, the temperatures are much higher.

This is due to the fact that the bottom surface is sited in the compressor, condenser and fan and the thickness of insulation was half of the other lateral surfaces (design project). Thus, an additional simulation was carried out where it was considered a double thickness of the insulation at the bottom wall. The same happens with the cover of the tank that doesn't have any kind of thermal insulation.

Doubling the insulation at the bottom of the tank, as well as the top wall, the benefits in energy consumption are displayed in Table 11, where the avoided $\mathrm{CO}_{2}$ emissions are also shown. The simulations were done with the EES (Engineering Equation Solver) software

Table 9 Parameters of the refrigeration system for different initial mass of ice.

\begin{tabular}{llllllll}
\hline $\begin{array}{l}\text { Initial lii9) } \\
\text { cyyyy of }\end{array}$ & $\begin{array}{l}\mathrm{COP}_{\mathrm{R}} \\
{[-]}\end{array}$ & $\begin{array}{l}\mathrm{COP}_{\mathrm{G}} \\
{[-]}\end{array}$ & $\begin{array}{l}\text { Running time of } \\
\text { compressor } \\
{[\mathrm{min} / \text { day }]}\end{array}$ & $\begin{array}{l}\text { Energy } \\
\text { (compressor and fan) } \\
{[\mathrm{Wh}]}\end{array}$ & $\begin{array}{l}\text { Stirring energy } \\
\text { and ice sensor } \\
{[\mathrm{Wh}]}\end{array}$ & $\begin{array}{l}\text { Daily energy } \\
{[\mathrm{Wh}]}\end{array}$ & $\begin{array}{l}\text { Annual } \\
\text { energy } \\
{[\mathrm{kWh}]}\end{array}$ \\
\hline $\begin{array}{l}\text { Initial mass of ice: } \\
10,21 \text { and 25 [kg] }\end{array}$ & 3.14 & 0.891 & 293 & 2,980 & 1,559 & 4,539 & 1,657 \\
\hline
\end{tabular}

Table 10 Decrease in energy consumption and avoided $\mathrm{CO}_{2}$ emissions for different initial mas of ice in the tank.

\begin{tabular}{|c|c|c|c|}
\hline & \multicolumn{3}{|c|}{ Initial mass of ice needed $[\mathrm{kg}]$} \\
\hline & 10 & 21 & 25 \\
\hline $\begin{array}{l}\text { Energy consumption: } \\
\text { (switched on for } 24 \mathrm{~h} \text { ) [Wh] }\end{array}$ & & 4,539 & \\
\hline $\begin{array}{l}\text { Energy consumption: } \\
\text { (switched off for } 12 \mathrm{~h} \text { ) [Wh] }\end{array}$ & 2,628 & 2,968 & 3,091 \\
\hline Energy savings per day [Wh] & 1,911 & 1,571 & 1,448 \\
\hline $\begin{array}{l}\text { Annual energy savings: } \\
\text { all systems [GW] }\end{array}$ & 27,900 & 22,937 & 21,141 \\
\hline $\begin{array}{l}\text { Reduction in emissions } \\
\text { of } \mathrm{CO}_{2} \text { per day }[\mathrm{kg}]\end{array}$ & 0.9 & 0.74 & 0.68 \\
\hline $\begin{array}{l}\text { Annual reduction in emissions } \\
\text { of } \mathrm{CO}_{2} \text { for all systems [ton] }\end{array}$ & 13,140 & 10,804 & 9,928 \\
\hline
\end{tabular}



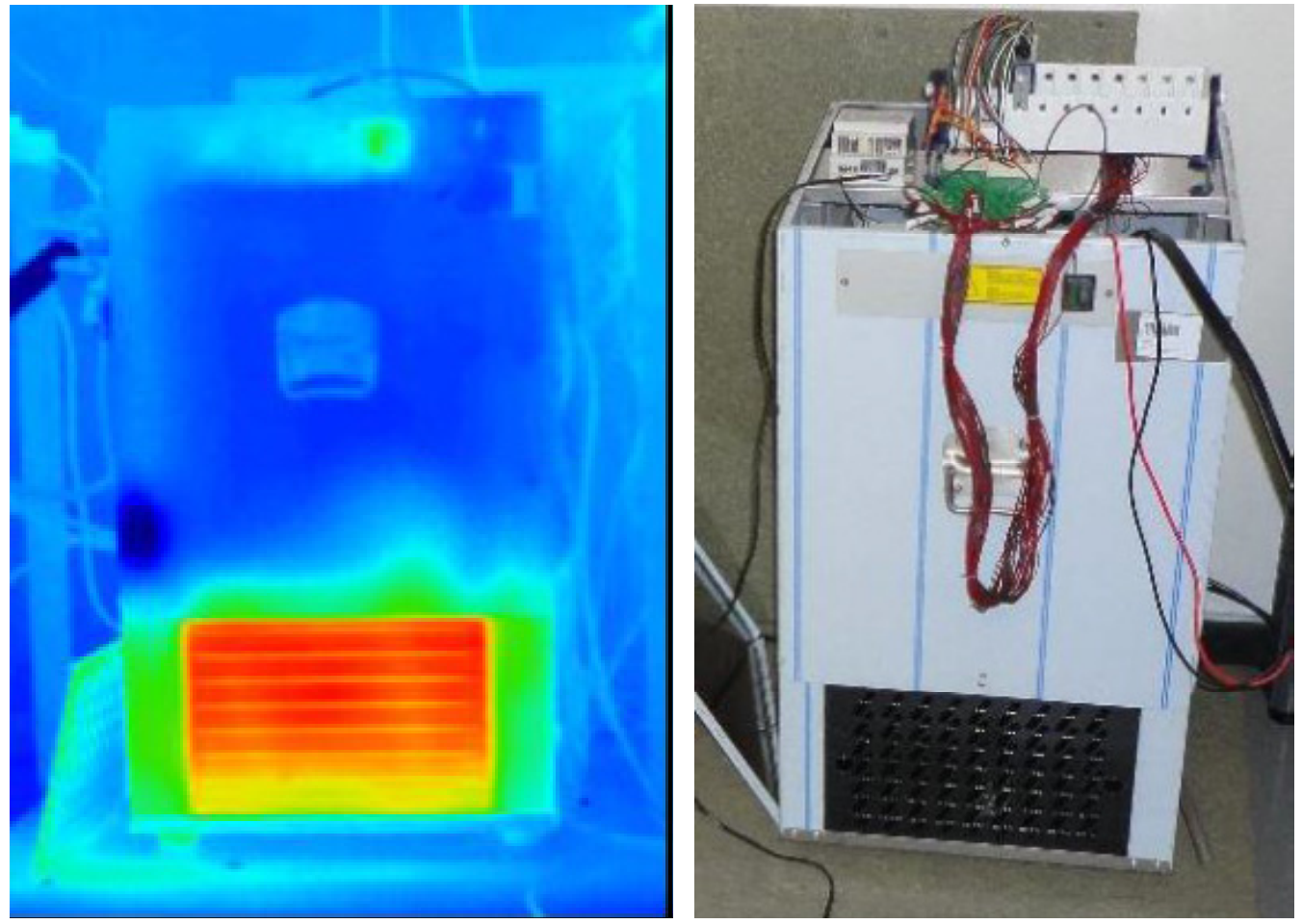

Fig. 8 Thermal image (left) of the refrigeration system (right).

[24]. Columns three to five show the daily and annual benefits regarding the energy consumption and the corresponding decrease of $\mathrm{CO}_{2}$ emission to the environment (these balances were done by taking into account the electricity generation mix in Portugal that results in a $\mathrm{CO}_{2}$ emission rate around $0.47 \mathrm{~kg}$ per $\mathrm{kWh}$ of electricity produced) [25]. Since the major player in the market, "Unicer Bebidas" the company that supported this research project, has in Portugal $40 \mathrm{k}$ systems like the one tested, the total amount of estimated savings is shown in the same table. Columns six and seven show the annual energetic savings for the total number of systems as well as the total reduction in $\mathrm{CO}_{2}$ emitted. So it is possible to conclude that this small improvement is really a good investment.

Stirring motor: the system presents a fourth inefficiency due to the fact that the stirring motor is located inside the iced water in the tank. It releases heat for $24 \mathrm{~h}$ hours with the actual configuration. This can be seen in thermography image (Fig. 9) (top view of the tank, in the middle) which shows the higher temperatures reached by the motor as well as the electronic equipment (bottom). These two factors contribute to decrease the COP of the system.

One way to overcome this problem and shown in Fig. 8, is to locate the refrigeration system itself (compressor and condenser) in the top of the deposit, being then also possible to locate the stirrer motor in the recess. A new prototype is under construction, but there are no results yet.

\section{Conclusion}

Two similar refrigeration systems based on the vapour compression cycle were analysed in this work. The first one was a household domestic refrigerator and the second one was a refrigeration system for draught beverages.

- The main conclusions to withdraw from the domestic refrigerators are:

With minor modifications it is possible to have a decrease in the inside air temperatures. These modifications simply consist in covering the external rear wall of the refrigerator and the compressor recess 
Table 11 Annual savings in energy and $\mathrm{CO}_{2}$ emissions if the tank is full insulated.

\begin{tabular}{|c|c|c|c|c|c|c|}
\hline $\begin{array}{l}\text { Energy } \\
\text { consumption } \\
\text { with actual } \\
\text { insulation } \\
\text { per system } \\
\text { [Wh] } \\
\end{array}$ & $\begin{array}{l}\text { Energy } \\
\text { consumption } \\
\text { with extra } \\
\text { insulation per } \\
\text { system [Wh] }\end{array}$ & $\begin{array}{l}\text { Daily } \\
\text { energy } \\
\text { savings } \\
\text { per system } \\
\text { [Wh] }\end{array}$ & $\begin{array}{l}\text { Annual } \\
\text { energetic } \\
\text { savings } \\
{[\mathrm{Wh}]}\end{array}$ & $\begin{array}{l}\text { Annual } \\
\text { savings of } \\
\mathrm{CO}_{2} \text { per } \\
\text { system }[\mathrm{kg} \\
\left.\mathrm{CO}_{2}\right]\end{array}$ & $\begin{array}{l}\text { Annual } \\
\text { energetic } \\
\text { savings } \\
\text { [GWh] }\end{array}$ & $\begin{array}{l}\text { Annual } \\
\text { savings } \\
\text { of } \mathrm{CO}_{2} \\
{[\text { ton }} \\
\left.\mathrm{CO}_{2}\right]\end{array}$ \\
\hline $5,563.04$ & $5,514.55$ & 48.49 & 17,699 & 8.32 & 0.708 & 333 \\
\hline
\end{tabular}

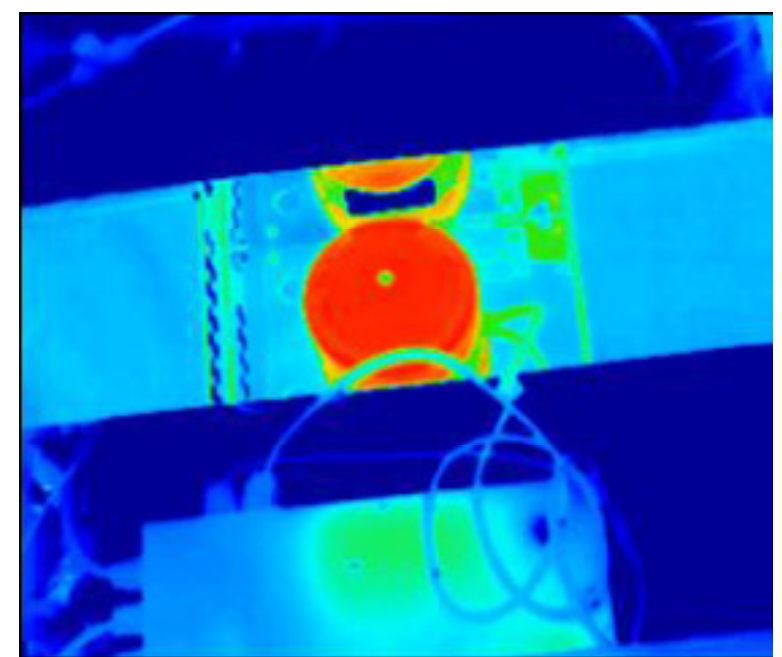

Fig. 9 Thermal image of the stirrer motor: top view of the equipment.

wall with a radiation shield avoiding in that way the radiation heat transfer from the condenser and the compressor to both external surfaces of the refrigerator. Results have shown that when those surfaces are covered with a sheet of aluminium foil, there is a significant decrease in the inside air temperatures of the refrigerator and of the freezer, about $2 \mathrm{~K}$. As a consequence, for the same internal air temperatures there will be a decrease in the compressor energy consumption with a decrease in the avoided $\mathrm{CO}_{2}$ emissions.

Another modification was carried out in order to improve its efficiency. It consists in building a plenum with a fan underneath the refrigerator to mechanically ventilate its base, where the compressor is located, and where the temperatures of external surfaces are higher: air is trapped in the compressor compartment and heated. Measurement of the temperatures in several points of inside and outside surfaces, as well as internal air, with and without ventilation, show that there is a decrease in temperature difference across the mentioned walls with the proposed technique. As a direct consequence, the heat transfer to the refrigerator inside will diminish too, leading to a decrease of compressor energy consumption. Power and energy consumption of the whole system (compressor and fan) were measured and it was possible to conclude that there were global savings in energy consumption with this solution. This leads to a direct decrease of $\mathrm{CO}_{2}$ emissions to the environment which varies from country to country due to their different electricity generation mixes.

The last study carried out was to evaluate the magnetic door seals that deteriorate with time, the loss of capacity of the magnetic band, the new cracks in the rubber and even the negligence of the users. This implies a larger air infiltration rate to the cabins and, as a direct consequence, a large energy consumption to overcome this increase. In this work it was quantified the influence of the magnetic door seal conditions upon the air infiltration rate in a domestic double door refrigerator as well as its overall heat balance. The first conclusion to withdraw from the tests is that the refrigerator cabin has almost twice the value of the air infiltration rate when compared with the freezer cabin (due to the much lower temperatures in this last cabin). So, special care must be dedicated to the seals of the refrigerators, where the temperatures are positive. A second conclusion is that the increase on the air infiltration rate due to the deterioration of magnetic seals of the doors is about $505 \%$ for the equipment tested, which reflects on the energy consumed by the compressor that shows a total increase of $341 \%$ on the electricity consumed. When 
the seals are new, $3.6 \%$ of the energy used to run the compressor is spent on the air infiltration and $96.4 \%$ on heat gains through the walls, while when they become leakier these percentages become respectively $18.5 \%$ and $81.5 \%$. As a consequence, there is a significant increase in the compressor energy consumption which implies higher running cost as well as worst environmental implications.

The main conclusions to withdraw from the refrigeration systems for draught drinks are:

Inefficiencies were detected in the system that may be fixed in the future. One is the absence of insulation on the top surface of the tank, as well as the larger temperature difference between the recess of the refrigeration system (where the compressor and condenser is located) and the iced water. So an improvement can be achieved by increasing the thermal insulation of the bottom surface, as well as to insulate the top cover which reduces the energy used of all the system.

As seen in Table 8, the internal heat exchange has a very low thermal efficiency of $1.5 \%$, so it must be changed.

If the system is switched off during the closing time of the establishments, the initial ice mass in the tank does a larger difference in the energy consumption of all the system as well as an avoided $\mathrm{CO}_{2}$ released to the environment (varies with kind of establishment and consumption pattern). In the maximum consumption pattern, a bar in summer time, it was proven that if the initial mass of ice was $10 \mathrm{~kg}$, it should be enough to overcome an extra peak consumption of beverage (this implies a decrease of energy consumed, with all positive consequences).

Also, if the refrigeration system is placed over the tank (and not bellow as it is actually), there will be savings in the heat transfer due to the fact that the stirring motor could be located outside of the iced water as well as the hot air of the recess would release heat to the environment temperature and not to the tank.
As beer is an organic fluid, it should be kept at low temperature $\left(<6{ }^{\circ} \mathrm{C}\right)$ in order to assure the best quality.

\section{References}

[1] International Institute of Refrigeration. 2015. "The Role of Refrigeration in the Global Economy." Presented at 29th International Institute of Refrigeration (IIR) Paris, France.

[2] Jie J., and Lee., W. L. 2015. "Experimental Investigations on the Use of Capillary Tube and Thermostatic Expansion Valve in Storage-Enhanced Heat Recovery Room Air-Conditioner." Energy and Buildings 101: 76-83.

[3] Bansal, P. K., and Chin, T. C. 2002. "Design and Modelling of Hot-Wall Condensers in Domestic Refrigerators." Applied Thermal Engneering 22 (14): 1601-17.

[4] Mota-Babiloni, A., Navarro-Esbrí, J., Barragán, A., Molés, F., and Perís, B. 2014. "Drop-in Energy Performance Evaluation of R1234yf and R1234ze (E) in a Vapor Compression System as R134a Replacements." Applied Thermal Engineering 71 (1): 259-65.

[5] Cabello, R., Sánchez, D., Llopis, R., Arauzo, I., and Torrella, E. 2015. "Experimental Comparison between R152a and R134a Working in a Refrigeration Facility Equipped with a Hermetic Compressor." International Journal of Refrigeration 60: 92-105.

[6] Bolaji, O., and Huan, Z. 2014. "Performance Investigation of Some Hydro-Fluorocarbon Refrigerants with Low Global Warming as Substitutes to R134a in Refrigeration Systems." Journal of Engineering Thermophysics 23: 148-57.

[7] Domanski, P. A., Didion, D. A., and Doyle, J. P. 1994. "Evaluation of Suction-Line/Liquid-Line Heat Exchange in the Refrigeration Cycle." International Journal of Refrigeration 17 (7): 487-93.

[8] Pottker, G., and Hrnjak, P. 2015. "Experimental Investigation of the Effect of Condenser Subcooling in R134a and R1234yf Air-Conditioning Systems with and without Internal Heat Exchanger." International Journal of Refrigeration 50: 104-13.

[9] Webb, R. L. 1998. Prediction of Condensation and Evaporation in Micro-Fin and Micro-Channel Tubes. In Heat Transfer Enhancement of Heat Exchangers. Kakac, S., Bergles, A. E, . Mayinger, F., and H. Yuncu, editors. Netherlands: Kluwer Academic Publishers. 529-50.

[10] Martínez-Ballester, S., Corberán, J., and Gonzálves-Maciá, J. 2013. "Numerical Model for Microchannel Condensers and Gas Coolers: Part I- Model Description and Validation." International Journal of 
Refrigeration 36 (1): 173-90.

[11] Kim, M. H., and Bullard, C. W. 2001. "Development of a Microchannel Evaporator Model for a $\mathrm{CO}_{2}$ Air-Conditioning System.” Energy 26 (10): 931-48.

[12] Piedrahita, C. A., Ciro-Velásquez, H. J., and Gómez-Botero, M. A. 2014. "Identification and Digital Control of a Household Refrigeration System with a Variable Speed Compressor." International Journal of Refrigeration 48 (1): 178-87.

[13] Afonso, C. 2016. "Heat and Water Vapour Transfer Trough the Envelope of a Cold Chamber." Journal of Environment Science and Engineering 5 (5): 243-53.

[14] Fluent Inc. 1998. "Fluent User's Guide" Version 4.0 Fluent Inc. Lebanon NH, USA.

[15] ASTM Standard E. 1980. "Standard Practice for Measuring Air Leakage Rate by the Tracer Dilution Method." Philadelphia, Pennsylvania: ASTM 741-80.

[16] Afonso, C., and Matos, J. 2006. "The Effect of Radiation Shields around the Air Condenser and Compressor of a Refrigerator on the Temperature Distribution Inside it." Int. J. Refrigeration 29 (7): 1144-51 (Elsevier Science).

[17] Afonso, C. F. 2013. "Household Refrigerators: Forced Air Ventilation in the Compressor and its Positive Environmental Impact.” Int. J. Refrigeration 36 (3): 1-9 (Elsevier Science).
[18] Bulletin of the IIR. N 2002-5, 2002. "Sustainable Development: Achievements and Challenges in the Refrigeration Sector." Bulletin of the IIR.

[19] Afonso, C. 2015. "Tracer Gas Technique for Measurement of Air Infiltration and Natural Ventilation: Case Studies and New Devices for Measurement of Mechanical Air Ventilation in Ducts." International Journal of Low Carbon Technologies 10 (3): 188-204.

[20] ASTM Standard, E. 1980. "Standard Practice for Measuring Air Leakage Rate by the Tracer Dilution Method.” Philadelphia, Pennsylvania: ASTM. 741-80.

[21] Afonso, C., and Castro, M. 2010. "Air Infiltration on Domestic Refrigerators: The Influence of the Magnetic Seals Conservation." International Journal of Refrigeration 33 (4): 856-67.

[22] Fernandes, J. 2013. "Experimentation and Optimization in a Beer Extraction System." M.Sc. Thesis. Porto University.

[23] Garcia, J. 2014. "Performance Improvement of Systems for Draught Drinks." M.Sc. Thesis. Porto University.

[24] EES. Engineering Equation Solver Software. Accessed Jan 20th, 2012. http://www.mhhe.com/engcs/mech/ees/.

[25] ADEPORTO (Porto Energy Agency). 2008. "Porto Energetic Mix." Accessed Sept 1st, 2008. http://adeporto.eu/. 